\title{
Are systolic function and ejection fraction interchangeable? New insights from cardiovascular magnetic resonance and in-vivo validation of mathematical models of LV function
}

\author{
Jonathan C Rodrigues ${ }^{1,2^{*}}$, Stephen Rohan ${ }^{3}$, Amardeep Ghosh Dastidar ${ }^{1}$, Amy E Burchell ${ }^{4}$, Laura E Ratcliffe ${ }^{4}$, \\ Emma C Hart ${ }^{4,2}$, Angus K Nightingale ${ }^{4}$, Julian F Paton ${ }^{2,4}$, Chiara Bucciarelli-Ducci ${ }^{1}$, Mark Hamilton', \\ Nathan E Manghat ${ }^{1}$, David H Maclver ${ }^{5,6}$
}

From 18th Annual SCMR Scientific Sessions

Nice, France. 4-7 February 2015

\section{Background}

Clinical studies have shown that many patients may have abnormally reduced myocardial shortening despite preserved ejection fraction (EF). Mathematical modeling explains this apparent paradox by demonstrating, that whilst myocardial shortening determines radial strain (RS), it is absolute wall thickness (AWT) rather than RS that determines EF. We sought in vivo cardiac MR (CMR) evidence to support the mathematical modeling theories.

\section{Methods}

We retrospectively analysed 39 CMR studies (28 hypertensive patients and 11 healthy volunteers [mean age: 47.4 \pm 13.0 , male: $56.4 \%]$ ) performed at $1.5 \mathrm{~T}$ (Avanto, Siemens). Ventricular volumes and EF were measured using established CMR techniques. Left ventricular wall thickness was measured at end-diastole (ED) and end-systole (ES) in the long-and short-axis cine views at the mid-cavity at the level of the papillary muscles. Measurements were repeated twice, 1 day apart. Longitudinal strain (LS) was estimated using a modified 6-point mean annular plane systolic excursion of the mitral valve from 3-chamber, 2chamber and 4-chamber cines. Subgroup analysis was performed by EDWT (Group $1<9 \mathrm{~mm}$ [ $\mathrm{n}=19$ ] and Group 2 $>9 \mathrm{~mm}[\mathrm{n}=20])$. Continuous variables were compared by Student $t$ tests and categorical variables by Fisher exact test (setting $p<0.05$ as significant).

${ }^{1}$ CMR Unit, NIHR Cardiovascular Biomedical Research Unit, Bristol Heart Institute, Bristol, UK

Full list of author information is available at the end of the article

\section{Definitions}

$\mathrm{AWT}=$ ES thickness - ED thickness.

$\mathrm{RS}=(\mathrm{AWT} / \mathrm{ED}$ thickness $) \times 100$.

Midwall circumferential fractional shortening $(\mathrm{mFS})=$ $(($ LVIDd+EDWT $)-($ LVIDs+H $)) /($ LVIDd+EDWT $) \times 100$ (\%), where $\mathrm{H}=\left((\text { LVIDd+EDWT })^{3}-(\text { LVIDd })^{3}+(\text { LVIDd })^{3} /\right.$ ${ }^{1 / 3}$-LVIDs, LVIDd $=$ left ventricular internal dimension in diastole, LVIDs = left ventricular internal dimension in systole and EDWT $=$ end diastolic wall thickness.

\section{Results}

Intra-observer variability for wall thickness measurements was good both both long-axis and short-axis measurements (intra-class correlation coefficient $=0.931$ ).

Significant positive correlation was demonstrated between EDWT and AWT $\left(\mathrm{r}^{2}=0.42, \mathrm{p}<0.0001\right)$. However, significant negative correlations were demonstrated between EDWT and RS $\left(\mathrm{r}^{2}=0.13, \mathrm{p}<0.05\right)$, between EDWT and longitudinal strain $\left(r^{2}=0.62, p<0.0001\right)$ and between EDWT and mFS $\left(\mathrm{r}^{2}=0.16, \mathrm{p}<0.05\right)$. Subgroup analysis by EDWT is demonstrated in Figure 1. Despite significant reductions in LS, mFS and trend towards lower RS, ejection fraction is significantly higher and indexed stroke volume is similar between in ventricles with EDWT $>9 \mathrm{~mm}$ compared to those $<9 \mathrm{~mm}$.

\section{Conclusions}

Myocardial systolic function and ejection fraction are not the same. Our study provides in-vivo validation of mathematical modeling predictions that significant LV 


\begin{tabular}{llll}
\hline \multicolumn{4}{l}{ Table 1: Subgroup analysis by end-diastolic wall thickness } \\
& $\begin{array}{l}\text { Group 1 } \\
(\mathbf{n}=\mathbf{1 9})\end{array}$ & $\begin{array}{l}\text { Group 2 } \\
(\mathbf{n}=\mathbf{2 0})\end{array}$ & P value \\
\hline End-diastolic wall thickness $(\mathrm{mm})$ & $<9$ & $>9$ & - \\
Mean EDWT $(\mathrm{mm})$ & $6.6 \pm 1.2$ & $11.7 \pm 2.5$ & $<0.0001$ \\
Ejection fraction (\%) & $61.9 \pm 5.9$ & $67.6 \pm 8.6$ & $<0.05$ \\
Indexed stroke volume (ml/m2) & $49.5 \pm 9.3$ & $53.2 \pm 11.0$ & $=0.2622$ \\
Mean longitudinal strain (\%) & $14.1 \pm 1.9$ & $9.5 \pm 2.8$ & $<0.0001$ \\
Mean radial strain (\%) & $68.8 \pm 22.8$ & $61.3 \pm 14.4$ & $=0.2304$ \\
Mean mFs (\%) & $20.0 \pm 3.6$ & $17.6 \pm 3.4$ & $<0.05$ \\
Mean AWT (mm) & $4.5 \pm 1.5$ & $6.8 \pm 1.3$ & $<0.0001$
\end{tabular}

(EDWT $=$ end-diastolic wall thickness, $\mathrm{mFS}=$ midwall fractional shortening, $\mathrm{AWT}=$ absolute wall thickness)

Figure 1 Subgroup analysis by end-diastolic wall thickness

systolic impairment (in the form of impaired LS, RS and $\mathrm{mFS}$ ) can be compensated for by significant increases in AWT thus maintaining indexed SV and EF. This finding has implications for the understanding the pathophysiology of heart failure with preserved ejection fraction, and its potential treatment.

\section{Funding}

NIHR Bristol Cardiovascular Biomedical Research Unit, Bristol Heart Institute.

JCLR: Clinical Society of Bath Postgraduate Research Bursary.

ECH: BHF grant IBSRF FS/11/1/28400.

\section{Authors' details}

${ }^{1}$ CMR Unit, NIHR Cardiovascular Biomedical Research Unit, Bristol Heart Institute, Bristol, UK. ${ }^{2}$ School of Physiology and Pharmacology, The University of Bristol, Bristol, UK. ${ }^{3}$ Medical School, The University of Bristol, Bristol, UK.

${ }^{4}$ Cardionomics Research Group, Bristol Heart Institute, Bristol, UK. ${ }^{5}$ Cardiology,

Taunton and Somerset Hospital, Taunton, UK. ${ }^{6}$ Biological Physics, The

University of Manchester, Manchester, UK.

Published: 3 February 2015
doi:10.1186/1532-429X-17-S1-P325

Cite this article as: Rodrigues et al: Are systolic function and ejection fraction interchangeable? New insights from cardiovascular magnetic resonance and in-vivo validation of mathematical models of LV function. Journal of Cardiovascular Magnetic Resonance 2015 17(Suppl 1): P325.

\section{Submit your next manuscript to BioMed Central} and take full advantage of:

- Convenient online submission

- Thorough peer review

- No space constraints or color figure charges

- Immediate publication on acceptance

- Inclusion in PubMed, CAS, Scopus and Google Scholar

- Research which is freely available for redistribution

Submit your manuscript at www.biomedcentral.com/submit 